\title{
A bias in the "mass-normalized" DTT response - an effect of non-linear concentration-response curves for copper and manganese
}

Jessica G. Charrier ${ }^{1}$, Alexander S. McFall ${ }^{1}$, Kennedy K-T Vu², James Baroi ${ }^{2}$, Catalina Olea ${ }^{2}$, Alam Hasson ${ }^{2}$, and Cort Anastasio ${ }^{1^{*}}$

${ }^{1}$ Department of Land, Air, and Water Resources, University of California, Davis.

${ }^{2}$ Department of Chemistry, California State University, Fresno.

*Corresponding Author

Dr. Cort Anastasio

University of California Davis

1 Shields Ave

3146 Plant and Environmental Sciences Building

Davis, CA 95616

Phone: (530) 754-6095

Email: canastasio@ucdavis.edu

1

\section{Abstract}

The dithiothreitol (DTT) assay is widely used to measure the oxidative potential of particulate matter. Results are typically presented in mass-normalized units (e.g., pmols DTT lost per minute per microgram PM) to allow for comparison among samples. Use of this unit assumes that the massnormalized DTT response is constant and independent of the mass concentration of PM added to the DTT assay. However, based on previous work that identified non-linear DTT responses for copper and manganese, this basic assumption (that the mass-normalized DTT response is independent of the concentration of PM added to the assay) should not be true for samples where $\mathrm{Cu}$ and $\mathrm{Mn}$ contribute significantly to the DTT signal. To test this we measured the DTT response at multiple PM concentrations for eight ambient particulate samples collected at two locations in California. The results confirm that for samples with significant contributions from $\mathrm{Cu}$ and $\mathrm{Mn}$, the mass-normalized DTT response can strongly depend on the concentration of PM added to the assay, varying by up to an order of magnitude for PM concentrations between 2 and $34 \mu \mathrm{g} \mathrm{mL}^{-1}$. This mass dependence confounds useful interpretation of DTT assay data in samples with significant contributions from $\mathrm{Cu}$ and $\mathrm{Mn}$, requiring additional quality control steps to check for this bias. To minimize this problem, we discuss two methods to correct the mass-normalized DTT result and we apply those methods to our samples. We find that it is possible to correct the mass-normalized DTT result, although the correction methods have some drawbacks and add uncertainty to DTT analyses. More broadly, other DTT-active species might also have non-linear concentration-responses in the assay and cause a bias. In addition, the same 
21 problem of $\mathrm{Cu}$ - and $\mathrm{Mn}$-mediated bias in mass-normalized DTT results might affect other measures of

22 acellular redox activity in PM and needs to be addressed.

23 Key Words: Dithiothreitol, oxidative potential, particulate matter, copper, manganese, quinones

\section{Introduction}

The dithiothreitol assay (DTT) is widely used to measure the oxidative potential of particulate matter (PM), which has been linked to the toxic effects of particles (Cho et al., 2005; Li et al., 2009;

27 Akhtar et al., 2010; Steenhof et al., 2011; Delfino et al., 2013). The DTT assay has been used to measure the oxidative potential from a variety of PM types including vehicle exhaust (Geller et al., 2006; Biswas et al., 2009; Li et al., 2009; McWhinney et al., 2013a), secondary organic aerosol (Verma et al., 2009a; Rattanavaraha et al., 2011; McWhinney et al., 2013b), nanoparticles (Sauvain et al., 2008), and ambient ultrafine, fine, and coarse PM (Cho et al., 2005; Hu et al., 2008; Steenhof et al., 2011; Verma et al., 2011; Verma et al., 2012; Saffari et al., 2014; Verma et al., 2014; Charrier et al., 2015; Verma et al., 2015a; Yang et al., 2015). New measurement techniques have adapted the DTT assay to allow high throughput detection of oxidative potential in PM (Sameenoi et al., 2012; Sameenoi et al., 2013; Fang et al., 2015). The DTT assay is popular due to the relative ease of use and the need for only basic, inexpensive laboratory equipment to analyze samples. In addition, there is some evidence for a correlation between the magnitude of DTT loss from PM and cellular markers of ROS (Yang et al., 2009; Steenhof et al., 2011).

Past work investigating redox-active chemical species in ambient PM has identified four quinones and seven transition metals that are able to oxidize DTT (Chung et al., 2006; Lin and Yu, 2011; Charrier and Anastasio, 2012; Verma et al., 2015b). Copper and manganese often appear to be

42 significant drivers of the DTT response in ambient PM, although this is not uniformly seen (Charrier and Anastasio, 2012; Charrier et al., 2015; Verma et al., 2015a)(Charrier and Anastasio, 2012; Verma et al., 2015; Charrier et al., 2015). For example, techniques to separate particle extracts into various chemical subfractions have found that the DTT response can be driven largely by organics, includinghumic-like substances (HULIS), oxidized quinones, and secondary organic species (Lin and Yu, 2011; Verma et al.,

47 2012; Verma et al., 2015a; Verma et al., 2015b); organic-bound transition metals might also be important. In addition, chamber studies have found that particulate organic peroxides in isoprenederived SOA are DTT active (Kramer et al., 2016). Organic carbon and water soluble organic carbon have been consistently correlated with DTT activity (Hu et al., 2008; Biswas et al., 2009; Verma et al., 2009a; 
51 Verma et al., 2009b; Saffari et al., 2014; Verma et al., 2014); however, the utility of correlation analysis is

52 limited in determining DTT-active species, in part because many species are covariate and because the 53 two most important DTT-active metals ( $\mathrm{Cu}$ and $\mathrm{Mn}$ ) have non-linear responses in the assay (Charrier and 54 Anastasio, 2012; Charrier et al., 2015).

DTT loss rates are typically reported as a mass-normalized response, with typical units of pmol-

56 DTT $\min ^{-1} \mu \mathrm{g}^{-1}-\mathrm{PM}$, to allow comparison of DTT responses between various samples. If the PM

57 concentration- DTT response curves are linear, then the DTT response in mass-normalized units will be 58 constant and independent of the PM mass added to the assay. However, if the PM concentration-DTT 59 response curves are non-linear, then the mass-normalized DTT response will also be nonlinear. Past work has identified that many organics and metals exhibit a linear DTT response (Charrier and Anastasio,

61 2012), and these species will dominate the DTT response in some particle samples. However since $\mathrm{Cu}$

62 and Mn display non-linear concentration-response curves (Charrier and Anastasio, 2012), in samples

63 where these metals make a significant contribution to the DTT result the mass-normalized DTT

64 response should depend on the concentration of PM added to the assay. Additionally, it is possible that

65 other chemical species, such as oxidized quinones or HULIS, might also exhibit non-linear concentrationresponse curves, which could bias the mass-normalized DTT result. on the concentration of ambient PM added to the assay. This paper has two components. In the first we measure the DTT response, and the concentrations of selected soluble metals and quinones, from ambient $\mathrm{PM}_{2.5}$ samples collected in Fresno and Claremont CA. We then use these data to determine

71 whether the mass-normalized DTT response varies with the PM mass concentration used in the assay.

72 In short, we find that it does for our samples, because $\mathrm{Cu}$ and $\mathrm{Mn}$ are important drivers of the DTT 73 responses. In the second component of the paper we present two techniques to correct the DTT 74 response and produce a robust mass-normalized result. In a separate publication, we apply the 75 correction technique to over 100 ambient $\mathrm{PM}_{2.5}$ samples collected at Fresno and Claremont, $\mathrm{CA}$, and 76 show substantial improvement in the interpretability of DTT results after correction (Anastasio et al., In 77 Preparation). 
$\mathrm{PM}_{2.5}$ samples were collected during July-August 2012 in Claremont, CA (34 ${ }^{\circ} 6^{\prime} 23.74 " \mathrm{~N}$;

$117^{\circ} 42^{\prime} 43.73^{\prime \prime} \mathrm{W}$, height $134 \mathrm{ft}$.), approximately $50 \mathrm{~km}$ east of downtown Los Angeles, and in JanuaryFebruary 2013 in Fresno, CA (36 48'55.88"N; 119²4'58.57"W, height $141 \mathrm{ft}$.), in California's Central Valley. Samples were collected on $260 \times 300 \mathrm{~mm}, 0.45 \mu \mathrm{m}$ pore, Teflon-coated glass filters (Tisch Environmental, Lot\#120618003) with a Hi-Volume PM2.5 sampler (Tisch Environmental TE-6070-2.5-HVS) at a rate of $1.13 \mathrm{~m}^{3} \mathrm{~min}^{-1}$. Prior to use, Teflon filters were individually cleaned with three $60-\mathrm{mL}$ aliquots of dicholoromethane (HPLC Grade; Sigma-Aldrich) and then baked for 2 hours. The final aliquot of dichloromethane was retained and analyzed as a blank. Cleaned filters were stored at $-20^{\circ} \mathrm{C}$ in aluminum envelopes until used. Each day samples were collected in three contiguous collection periods: morning (7 a.m.- 1 p.m.), afternoon (1 p.m.- 6 p.m.), and night ( 6 p.m.- 7 a.m.). The eight samples used for the analysis, including sample location and date and time of sampling, are described in Table 1.

A strip of PM sample, approximately 2.5 by $20 \mathrm{~cm}$, was cut from the larger filter using a new paper cutter cleaned with 95 percent ethanol before use and after each cut. Blank filters were cut first to avoid contamination. Each filter piece was wrapped in combusted aluminum foil, placed inside a sturdy envelope, and stored in an air-tight black bag at $-20^{\circ} \mathrm{C}$ until use. All samples were analyzed for DTT loss and soluble metals concentration between May and June 2013 and quinone analysis was completed in May 2014. Though the samples were stored for 4-9 months before DTT analysis, our freezer PM storage conditions should retain semivolatile organic species.

The DTT assay was carried out in Chelex-treated phosphate buffer to remove trace metal contamination as described previously (Cho et al., 2005; Charrier and Anastasio, 2012). We warm the PM sample of known mass for 2 minutes in a $7.0 \mathrm{~mL}$ amber glass vial then add $50 \mu \mathrm{L}$ of a 50:50 vol/vol solution of 2,2,2-trifluoroethanol (TFE) and Milli-Q water to the filter as a wetting agent (Vidrio et al., 2009). We start the reaction by adding $3.0 \mathrm{~mL}$ of $100 \mu \mathrm{M}$ DTT in $0.10 \mathrm{M}$ phosphate buffer $(77.8 \mathrm{mM}$ $\mathrm{Na}_{2} \mathrm{H}_{2} \mathrm{PO}_{4}$ and $22.2 \mathrm{mM} \mathrm{KH}_{2} \mathrm{PO}_{4}, \mathrm{pH}$ 7.4; Chelex-treated) and measure the concentration of DTT at 5, 10 and 15 minutes to calculate the linear rate of DTT loss. There is no difference in DTT rates with and without TFE for the solution blank, $\mathrm{Cu}(\mathrm{II}) \mathrm{SO}_{4}$ positive control, and a $0.050 \mu \mathrm{M}$ phenanthrenequinone stock (data not shown). The TFE solution was added to all solution blanks, filter blanks, and the Cu positive controls for consistency. various filter sizes. The positive control consisted of $0.50 \mu \mathrm{M} \mathrm{Cu}(\mathrm{II}) \mathrm{SO}_{4}$, which gave an average blank- 
111

112

113

114

115

116

117

118

119

120

121

122

123

124

125

126

127

128

129

130

131

132

133

134

135

136

137

138

139

corrected DTT rate of $0.75 \pm 0.09 \mu \mathrm{M} \mathrm{DTT} \min ^{-1}(n=30)$. The average solution blank across all solutions was $0.20 \pm 0.1 \mu \mathrm{M}$ DTT $\min ^{-1}(n=60)$. PM samples were corrected for both the daily solution blank ( $n=2$ per day) and the filter blank. The filter blank did exhibit a small DTT response that was dependent on the surface area of the filter added. For a given sample, the rate of DTT loss by the solution-blankcorrected filter blank was equal to $0.0401 \pm 0.003 \mu \mathrm{M} \mathrm{min}^{-1}$ times the surface area of the filter used for the sample (in $\mathrm{cm}^{2}$ ) (Supplemental Section S1).

PM samples were cut into reproducible sections using two different square punches, which produced filter squares with a surface area of either $2.279 \pm 0.078 \mathrm{~cm}^{2}$ or $3.985 \pm 0.168 \mathrm{~cm}^{2}$. The $\mathrm{PM}_{2.5}$ mass of each filter section was calculated based on the mass of PM on the entire filter (which was measured as part of ambient sampling), and the relative surface area of the punch to the entire sampled portion of the filter, assuming even distribution of the PM over the filter surface. The filter punch produces two sizes, so provides only two PM extract mass concentrations. To obtain additional mass concentrations the filter punch (of known size) was cut into multiple smaller pieces (of different sizes). We calculated the mass loading of each smaller piecegravimetrically, by first weighing the full filter punch, then weighing each of the cut sections to identify the relative fraction of the total.

\subsection{Soluble Metal Measurements}

After the final DTT measurement the samples were removed from the heating block and allowed to cool for 5 minutes. An aliquot of each solution was filtered through a $0.22 \mu \mathrm{M}$ PTFE syringe filter (Tisch Environmental) and diluted 1:10 with 3\% nitric acid to adequately dilute the salts prior to analysis. Filter blanks and daily solution blanks were treated in the same way as PM samples. Soluble metals were analyzed by the UC Davis Interdisciplinary Center for Plasma Mass Spectrometry (ICPMS.UCDavis.edu) using an Agilent 7500CE ICP-MS (Agilent Technologies, Palo Alto, CA). Standards were diluted from a Certiprep ME2A standard (SPEX CertiPrep) to 0.25 ppb, 0.5 ppb, 1 ppb, 10 ppb, 100 ppb, 200 ppb and 500 ppb respectively in 3\% nitric acid. A NIST 1643E Standard metals calibration (National Institute of Standards and Technology) was analyzed initially and QC standard consisting of ME2A at $100 \mathrm{ppb}$ were analyzed every 12th sample as quality controls. Sc, Y, and Bi Certiprep standards (SPEX CertiPrep) were diluted to $100 \mathrm{ppb}$ in $3 \%$ nitric acid and introduced by peripump as an internal standard.

\subsection{Quinone Measurements}


Filter samples were cut into 2 inch by 2 inch squares in triplicates, and spiked with $200 \mu \mathrm{L}$ of $1 \times 10^{-5} \mathrm{M}$ deuterated phenanthrene as an internal standard and $200 \mu \mathrm{L}$ of 2,2,2- trifluoroethanol (Sigma

142 Aldrich, T63002 $\geq 99 \%$ ) as a wetting agent. Filters were then extracted into freshly-prepared Surrogate

143 Lung Fluid (SLF) containing $114 \mathrm{mM} \mathrm{NaCl}, 10 \mathrm{mM}$ phosphate (pH 7.4), $200 \mu \mathrm{M}$ ascorbate, $300 \mu \mathrm{M}$

144 citrate, $100 \mu \mathrm{M}$ urate, and $100 \mu \mathrm{M}$ glutathione (Charrier and Anastasio, 2011) by slowly rocking for two

145 hours after which the SLF was removed into a vial for organic extraction with $15 \mathrm{~mL}$ of dichloromethane.

146 The quinone extraction solution differed slightly from the DTT solution because quinone samples will

147 also be compared to oxidative measurement of hydroxyl radical and hydrogen peroxide in future work.

148 Both the SLF and DTT solutions are both $\mathrm{pH} 7.4$, have the same ionic strength, and utilize TFE, which

149 effectively removes particles from the filter substrate; in both extract solutions we expect there will be

150 both particulate-phase and water-soluble quinones. We do not expect quinone results to differ

151 between these two solutions, but have not confirmed this. The DCM layer was transferred into a

152 borosilicate glass tube with an end point volume of $2.0 \mathrm{~mL}$. Three extracts for each sample were

153 combined into one collection vessel and evaporated to dryness using a Labconco $\mathrm{N}_{2}$ Blowdown Rapid

154 Evap instrument. All samples were reconstituted with $\mathrm{DCM}$ to $2.0 \mathrm{~mL}$ and stored at $-20^{\circ} \mathrm{C}$ prior to 155 derivatization and analysis.

Sample preparation and analysis followed the procedure utilized previously in our lab (Chung et

157 al., 2006). In brief, four quinones (1,4-chrysenequinone, phenanthraquinone, 1,2-naphthoquinone, 1,4-

158 naphthoquinone) were converted to their diacetylated derivatives following the procedure of Cho et al.

159 (2004). The remaining quinones were analyzed without derivatization. Samples were analyzed by gas

160 chromatography-mass spectrometry (GC-MS, Agilent 6890/5973) using the method described in our

161 earlier work (Chung et al., 2006).

$162 \quad 2.5$ Updated Cu Concentration-Response Curve

163 During initial data analysis we determined that the equation of the $\mathrm{Cu}$ concentration-response

164 curve from our previous work (Charrier and Anastasio, 2012) generally underpredicted the DTT

165 responses we measured at low $\mathrm{Cu}$ concentrations. The $\mathrm{Cu}$ concentration-response data was re-analyzed

166 to provide better DTT prediction at low Cu concentrations. To do this we used the same exponential

167 regression function form as in our previous work, but restricted the fit to data between 0 and $1.5 \mu \mathrm{M}$

$168 \mathrm{Cu}$, the typical range for our ambient PM extracts (Supplemental Section S2). The updated Cu

169 concentration-response used for this analysis is

$$
Y=0.982 X^{0.3279}
$$


171 where $Y$ is the DTT response in $\mu \mathrm{M} \mathrm{min}{ }^{-1}$ and $X$ is the soluble Cu concentration in $\mu \mathrm{M}$.

\section{Results and Discussion}

173 3.1 DTT Response from a Hypothetical PM Sample

174

175

We start by examining a hypothetical particle sample to illustrate what we expect for the overall rate of DTT loss, as well as the rates from individual DTT-active species, as a function of PM mass concentration $\left(1-60 \mu \mathrm{gL}^{-1}\right)$ in the assay solution. This hypothetical PM sample is not meant to represent a specific ambient PM sample, but rather illustrates the mathematical underpinnings of our hypothesis. The hypothetical PM extract at $10 \mu \mathrm{g}-\mathrm{PM} \mathrm{mL}^{-1}$ is assumed to contain four DTT-active species: $100 \mathrm{nM} \mathrm{Cu}, 150 \mathrm{nM} \mathrm{Mn}, 150 \mathrm{nM}$ Co, and $5 \mathrm{nM}$ PQN. The concentration of each species is assumed to be linearly related to the PM mass concentration; that is, a doubling of PM mass concentration in the extract will double the resulting extract concentration of each species. While the chemical composition is linearly related to PM mass, the DTT response $\left(\mu \mathrm{M} \mathrm{min}^{-1}\right)$ is non-linear for $\mathrm{Cu}$ and $\mathrm{Mn}$, and is linear for Co and PQN (Figure 1a), a consequence of their concentration-response curves (Charrier and Anastasio, 2012). The total DTT response, which is the sum of the lines from the individual species, is non-linear due to the contributions from $\mathrm{Cu}$ and $\mathrm{Mn}$ (Figure 1a).

We then take the individual and total rates in Figure 1a and divide by the PM mass concentration in the hypothetical PM extract to determine the mass-normalized DTT response (in units of pmols DTT $\min ^{-1} \mu \mathrm{g}^{-1}-\mathrm{PM}$; Figure $1 \mathrm{~b}$ ). The mass-normalized DTT responses from PQN and Co are constant as a function of PM concentration added to the assay (since these species have linear concentration-response curves), while the mass-normalized DTT responses for $\mathrm{Cu}$ and $\mathrm{Mn}$ are not constant (since these species have non-linear concentration-response curves). Because of this, for this single hypothetical PM sample, the total mass-normalized DTT response varies between 450 and 30 pmols DTT $\min ^{-1} \mu \mathrm{g}^{-1}$-PM and is strongly dependent on the concentration of PM added to the assay, especially at lower mass concentrations. If similar behavior occurs for ambient PM extracts, then the mass-normalized DTT rate would be highly biased, and would be essentially useless for comparing DTT responses among samples measured at different PM extract mass concentrations. DTT results expressed in air-volume-normalized units (e.g., pmols DTT $\mathrm{min}^{-1} \mathrm{~m}^{-3}$-air) are similarly biased by the mass concentration used in the assay; this is because the air-volume-normalized result is equivalent to the mass-normalized DTT rate (pmols DTT $\mathrm{min}^{-1} \mu \mathrm{g}^{-1}-\mathrm{PM}$ ) multiplied by the airborne PM mass concentration ( $\mu$ g-PM m ${ }^{-3}$-air). 


\subsection{DTT Response as a Function of Ambient PM Concentration}

To understand if the DTT response in ambient $\mathrm{PM}_{2.5}$ samples can behave similarly to the hypothetical PM described above, we measured the DTT response as a function of PM mass concentration for eight $\mathrm{PM}_{2.5}$ samples collected at two locations in California. The location, date, time and range of PM concentrations used in the DTT assay are in Table 1. Based on the measured chemical composition of the PM, and the concentration-response curves measured previously (Charrier and Anastasio, 2012), we can calculate the expected DTT response from soluble metals and quinones in each sample. For $\mathrm{Cu}$, we use the updated concentration-response curve discussed in the Methods section (equation 1). If the measured DTT response is larger than the sum of the calculated DTT responses from each species, then the remaining DTT response is labeled as "unknown". This unknown DTT response represents DTT-active species that have not been quantified in our particles, such as oxygenated quinones, HULIS, or other unidentified species. For example, 5-hydroxy-1,4-naphthoquinone, an oxygenated derivative of 1,4-naphthoquinone, has been identified as DTT active (Verma et al., 2015b) but was not quantified in this work and so any contribution would be included in "unknown". Figure 2 shows the contribution of measured metals and quinones to total DTT response for each sample at one PM mass concentration. In all samples the DTT response is primarily attributed to $\mathrm{Cu}$, while $\mathrm{Mn}$, quinones (primarily PQN) and unknown species generally contribute as well.

Figure 3 shows the measured DTT response from each PM sample, now measured at multiple concentrations and expressed using two different units. The non-mass-normalized DTT response (in $\mu \mathrm{M}$ $\min ^{-1}$ ) appears somewhat linear as a function of PM mass added to the vial, however the data do not pass through the origin (Figure 3a). In contrast, the mass-normalized DTT response (in units of pmols DTT $\left.\min ^{-1} \mu g^{-1}-P M\right)$ is strongly dependent on the concentration of PM added to the vial (Figure 3b), showing similar behavior to the theoretical PM sample in Figure 1. These data show that the massnormalized DTT response is not constant as a function of the mass of PM added to the DTT assay, at least for samples with significant contributions to DTT activity from $\mathrm{Cu}$ and $\mathrm{Mn}$. For a given sample, the resulting mass-normalized DTT response varies by up to a factor of 6 depending on the concentration of PM added to the assay, with this variance largely determined by the range of PM mass concentrations used. However, the different samples all largely follow the same curve in Figure $3 b$, a consequence of Cu being the dominant redox-active species in each sample; over the entire mass range used for the eight samples $(1.6-66 \mu \mathrm{g} / \mathrm{mL})$, the mass-normalized DTT rate varies by a factor of 8 . 
To investigate this mass dependence more closely, we next focus on one sample, C12, that we

232 studied with the greatest number of different mass concentrations. Figure 4 shows the measured DTT

233 response, the calculated DTT response from $\mathrm{Cu}$, and the measured concentration of soluble $\mathrm{Cu}$ in each

234 sample in both raw (Figure 4a) and mass-normalized units (4b). All samples are from the same PM filter,

235 with the only difference being the size of the filter piece used. As expected, the soluble $\mathrm{Cu}$

236 concentration varies linearly with PM concentration in the vial (Figure 4a); thus the mass-normalized Cu concentration ( $\mu \mathrm{g} \mathrm{Cu} \mathrm{g}^{-1}-\mathrm{PM}$ ) is independent of the concentration of PM added to the assay within error (Figure 4b). The calculated DTT rate from Cu accounts for most of the measured DTT response, and behaves like the measured DTT response in both units. The measured mass-normalized DTT rate from sample C12 varies between 260 and 40 pmols DTT $\min ^{-1} \mu \mathrm{g}^{-1-} \mathrm{PM}$, decreasing with increasing concentration of PM added to the assay. The fact that the soluble Cu concentration (in $\mathrm{nM}$ ) in each sample extract is linearly proportional to the PM mass concentration (Figure 4a) indicates the massdependent DTT result in Figure $4 \mathrm{~b}$ is not an artifact of PM extraction or an effect of solubility. Additionally, the fact that the measured DTT response follows near identical behavior to the calculated DTT response from $\mathrm{Cu}$, and is similar to Figure 1, indicates that the non-linear $\mathrm{Cu}$ concentrationresponse is driving the result.

While these results indicate a potentially significant artifact in the DTT assay, it is important to note the mass-normalized DTT response will be unbiased (i.e., independent of PM mass concentration) in some cases. For example, samples with low $\mathrm{Cu}$ and $\mathrm{Mn}$ contents, where most DTT response is attributable to species that have a linear concentration-response should be relatively unbiased. Thus diesel PM samples, or laboratory-generated samples of secondary organic aerosol from organic precursors, should have low amounts of $\mathrm{Cu}$ and $\mathrm{Mn}$ and thus may produce a robust mass-normalized DTT response. Additionally, samples that are studied near the DTT target concentration of $10 \mu \mathrm{g}-\mathrm{PM}$ $\mathrm{mL}^{-1}$ (discussed below) will show less bias, especially if Cu concentrations are moderate, as we observed

255 in a different ambient PM sample set (Charrier et al., 2015).

\subsection{Correction of the Mass-Normalized DTT Response}

Comparing DTT responses among samples requires a robust mass-normalized DTT result.

258 Because the mass-normalized response is a function of mass, meaningfully comparing rates requires 259 either that researchers measure the DTT response at one standard PM mass concentration for all 260 samples, or that a technique is developed to calculate DTT responses at a standard mass concentration. 261 This mass concentration must be constant for all studies in order to compare DTT data; this can be 
difficult considering that reported DTT rates span a wide range, from 5 to $500 \mathrm{pmol} / \mathrm{min} / \mu \mathrm{g}$ PM (Charrier and Anastasio, 2012; Verma et al., 2015a). We propose a standard of expressing massnormalized DTT results relative to an extract concentration of $10 \mu \mathrm{g}-\mathrm{PM} \mathrm{mL} \mathrm{L}^{-1}$ of DTT solution; while there is no "right" concentration for the standard, this proposed extract concentration provides an adequate DTT response for typical ambient PM in our experience but uses relatively little sample.

As described above, the first option to get a robust mass-normalized DTT response is for the community to measure all samples at a standard PM mass concentration in the DTT assay. However, this approach is often impractical, as it would require a consistent PM mass in all DTT extracts regardless of PM collection method and ambient mass concentration. However, if possible to add $10 \mu \mathrm{g} \mathrm{PM} \mathrm{mL}{ }^{-1}$ in each DTT assay, then this method would theoretically be the most accurate, as it would not require a correction calculation. However, significant post-sampling preparation might be necessary to add a specific mass of PM to the DTT assay, which might affect the results. For example, the removal of PM from sampling substrates can introduce artifacts, such as the loss of semi-volatile quinones during evaporation or drying steps. For these reasons, post-sampling processing to add $10 \mu \mathrm{g} \mathrm{mL}^{-1}$ to the DTT assay may introduce other significant errors, which would need to be examined.

The second option for obtaining a robust DTT result is to use variable PM masses in the extracts but then correct the measured rate to account for the non-linear concentration-response curves for $\mathrm{Cu}$ and $\mathrm{Mn}$. Here we consider two alternate methods for this, both where the expected DTT response is calculated to the standard PM mass concentration of $10 \mu \mathrm{g} \mathrm{mL}^{-1}$ in the extract. The first method, "interpolation", requires measuring the DTT response at multiple PM mass concentrations and interpolating the DTT response to a PM concentration of $10 \mu \mathrm{g} \mathrm{mL}^{-1}$. The second method, "calculation", requires measuring the DTT response, and concentrations of DTT-active species, in a sample at one mass concentration and using published concentration-response curves to calculate the expected result at the standard mass concentration of $10 \mu \mathrm{g} \mathrm{mL}^{-1}$. The first of these, the "interpolation" method, has the advantage of not requiring chemical analysis, although it requires running each sample at multiple mass concentrations, ideally in a narrow range around an extract mass concentration of $10 \mu \mathrm{g} \mathrm{m}^{-1}$. We then assume a linear relationship between the raw DTT response (in $\mu \mathrm{M} \mathrm{DTT} \mathrm{min}^{-1}$ ) and the mass concentration of PM and use this line to estimate the rate at $10 \mu \mathrm{g} \mathrm{mL}^{-1}$ of PM. As shown in Figure 5 for the eight variable mass samples, there is generally a relatively linear relationship between measured DTT response $\left(\mu \mathrm{M} \mathrm{min}^{-1}\right)$ and the concentration of PM added to the assay. However, the results will actually follow a curve similar to the total DTT response in Figure 1a, where the magnitude of curvature 
depends on the $\mathrm{Cu}$ and $\mathrm{Mn}$ contents of the PM. This non-linear relationship is subtle but apparent in sample C12 (Figure 5a) where the linear regression does not fit the curvature of the measured DTT response, and the corrected DTT response at $10 \mu \mathrm{g} \mathrm{mL}^{-1}$ is lower than expected from the samples that are closest in concentration. Though the DTT relationship is non-linear with PM mass, we assume a linear relationship to maintain the simplicity of the "interpolation" method, and avoid having to measure $\mathrm{Cu}$ and $\mathrm{Mn}$ in the PM sample. This assumption appears to add minimal uncertainty if the DTT response is measured at PM concentrations near $10 \mu \mathrm{g} \mathrm{mL}^{-1}$. If PM samples are measured at concentrations quite different than $10 \mu \mathrm{g} \mathrm{m}^{-1}$, or do not surround this value, then uncertainty increases, and the results may not be valid. For samples with measurements of DTT response above and below $10 \mu \mathrm{g} \mathrm{mL}^{-1}$, as in sample $\mathrm{C} 12$, a corrected result using the linear interpolation of the points immediately surrounding $10 \mu \mathrm{g} \mathrm{mL} \mathrm{L}^{-1}$ will provide the most accurate result.

A second potential source of error in the "interpolation" method is illustrated in samples C19, F17, and F28 (Figures 5b, 5f, and 5g respectively), where the measured DTT responses do not encompass $10 \mu \mathrm{g} \mathrm{mL}^{-1}$. A corrected DTT response extrapolated far outside the measured DTT response can increase the uncertainty in the corrected DTT response, as the divergence from linear will become increasingly large. This is illustrated in Figure 5g, where the "interpolation" method assumes a linear response (black X), while the calculated DTT response based on the chemical composition of the sample (based on the composition of the sample at 65.9 ug PM mL ${ }^{-1}$ of DTT solution) shows a curved result (orange line).

Thus, the "interpolation" method in this sample likely overestimates the corrected mass-normalized DTT response. On the other hand, extrapolating from very low masses to $10 \mu \mathrm{g} / \mathrm{mL}$ could lead to an overestimate of the DTT response if the sample has significant curvature. Thus, while the "interpolation" method can produce accurate results when DTT measurements closely surround the 10 $\mu \mathrm{g} \mathrm{mL}^{-1}$ target and are interpolated over small PM mass differences, accuracy cannot be assured in other cases.

The second method, "calculation", requires measuring the DTT response at only one PM mass concentration (preferably near $10 \mu \mathrm{g} \mathrm{mL}^{-1}$ ), but necessitates chemically characterizing $\mathrm{Cu}$ and $\mathrm{Mn}$ in the sample. $\mathrm{Cu}$ and $\mathrm{Mn}$ concentrations are assumed to vary linearly with the PM mass added to the vial, allowing calculation of their concentrations at $10 \mu \mathrm{g}-\mathrm{PM} \mathrm{mL}^{-1}$. These normalized concentrations are then used in the DTT concentration-response equations (Charrier and Anastasio (2012) and equation 1) to calculate their DTT responses at $10 \mu \mathrm{g} \mathrm{m}^{-1}$. Since other DTT-active species exhibit linear concentration-response curves (Charrier and Anastasio, 2012), their DTT responses are assumed to be 
proportional to PM mass concentration. Similarly, we assume that the concentration-response curves

325 for the unknown species are linear. However, some of the responses for unknown DTT-active species

326 might be non-linear, which would lead to errors in calculation. Therefore, samples with a large

327 contribution from unknown species may require more analysis to ensure accurate normalization. The

328 "calculation" method has the advantage over the "interpolation" method that a wider variety of PM

329 masses could be used in the DTT assay without sacrificing accuracy, because the "calculation" method is

330 able to account for the curve in DTT response as a function of PM concentration (e.g., Figure 5g).

331 However, this method relies on measuring trace $\mathrm{Cu}$ and $\mathrm{Mn}$ concentrations, which often have significant

332 error. Propagating this error through to the DTT rate results in larger errors for the calculated mass-

333 normalized DTT result at $10 \mu \mathrm{g} / \mathrm{mL}$.

For a given sample, using the "calculation" method with any mass concentration of PM used in the assay should result in the same corrected mass-normalized DTT response. To test this, we calculated the corrected mass-normalized DTT result for each measured DTT response at the different concentrations of PM mass used for a given sample. As shown in Figure 6, the "calculation" method gives a relatively consistent corrected mass-normalized DTT response, independent of the starting concentration of PM used. The exception is for very low PM mass concentrations, which appear to consistently diverge from the results of the other masses (Figures $6 a, b, c$, and d). Based on this result it appears that the "calculation" method cannot be used for samples measured with a PM mass concentration below approximately $4 \mu \mathrm{g}-\mathrm{PM} \mathrm{mL} \mathrm{mL}^{-1}$.

\subsection{Comparisons of the two Correction Methods}

In Figure 7 we compare the corrected mass-normalized DTT results (using both correction methods) to the measured DTT data for each sample. The two methods provide very similar corrected mass-normalized DTT responses for samples that did not require extrapolation beyond the measured data (i.e., Figure 7 excluding $f$ and g). Under these conditions both methods appear to provide a similar 348 level of accuracy. The results begin to diverge for samples F17 and F28 (Figures $7 \mathrm{f}$ and g), where the corrected results are extrapolated far from the measured values. For these two samples the "calculation" method result is more accurate than the "interpolation" method, because the "calculation" method is able to account for the curvature in the DTT response as a function of PM

352 concentration (e.g., Figures 1 and 5a). This illustrates one of the main drawbacks of the "interpolation" method: accuracy cannot be assured if results are extrapolated outside of measured values. 
The dependence of the mass-normalized DTT response on the PM mass concentration in the assay extract is an unwelcome complication. While this mass dependence will likely only be significant in samples where $\mathrm{Cu}$ and $\mathrm{Mn}$ account for a significant fraction of the DTT response, these transition metals appear to be widely important for DTT activity in ambient PM (Charrier and Anastasio, 2012; Charrier et al., 2015; Verma et al., 2015a). In addition, it is possible that currently unidentified DTTactive species also have non-linear concentration-response curves. Since DTT studies generally do not report the mass concentration of PM used for each sample, it is impossible to assess the significance of the PM extract mass dependence for past DTT results. In general, the mass-dependence artifact will make it appear that samples studied at a lower PM mass concentration in the DTT assay have a higher mass-normalized response, confounding the interpretation of DTT data for sample sets that use a range of PM mass concentrations in the assay. For example, in studies where the same air volume is collected and the same filter punch size is used for every sample (both common practices), the mass of PM in the DTT extract will be proportional to the ambient PM mass concentration. In these cases, the massdependence artifact could therefore make it appear that the mass-normalized DTT response is inversely correlated with ambient PM concentration.

The DTT assay has also been adapted for on-line analysis of ambient PM (Sameenoi et al., 2012; Sameenoi et al., 2013; Koehler et al., 2014). These techniques are likely susceptible to the same artifact in the mass-normalized response that we observe here, because this artifact is directly tied to the nonlinear concentration- response curves for $\mathrm{Cu}$ and $\mathrm{Mn}$ in the DTT assay. While the DTT corrections we discuss above cannot currently be applied to the on-line analyses, given the mass sensitivity of the massnormalized DTT responses, it is essential to analyze the potential for this artifact to affect these methods. This could be done, for example, using PM that would exhibit the artifact, such as ambient PM with modestly high $\mathrm{Cu}$ and Mn concentrations; in contrast, the artifact is unlikely to appear in lab SOA, dust, or diesel PM samples that might be used to calibrate or validate the techniques. Correction of the DTT assay in on-line techniques may be particularly challenging, but is no less important in order to provide an accurate interpretation of oxidative potential from the DTT assay.

Unfortunately, the mass dependence of the mass-normalized result in the DTT assay likely also occurs in other assays. Indeed, any assay where an important redox-active chemical species exhibits a non-linear concentration-response curve should suffer from a similar bias. For example, Cu has nonlinear concentration-response curves in assays that measure the generation of hydroxyl radical (' $\mathrm{OH})$ 
(Vidrio et al., 2008; Charrier and Anastasio, 2015) and hydrogen peroxide (HOOH) (Shen et al., 2011;

386 Charrier et al., 2014) in a cell-free surrogate lung fluid. Since $\mathrm{Cu}$ is a major component of both $\mathrm{OH}$ and $\mathrm{HOOH}$ generation from ambient PM (DiStefano et al., 2009; Vidrio et al., 2009; Shen and Anastasio, 2011; Shen et al., 2011; Shen and Anastasio, 2012; Richards-Henderson et al., 2015), the measured rates are likely affected by the PM mass employed in each extract, although this has not been examined. Further work is necessary to determine the extent of this bias and to examine whether the methods for correcting DTT data we describe here for DTT can apply to other assays.

\section{Conclusions}

We have shown that ambient $\mathrm{PM}_{2.5}$ samples collected at two different sites in California exhibit bias in the mass-normalized DTT result, which confounds the ability to compare results among samples if results are not corrected. This bias is a consequence of the non-linear concentration-response curves of soluble copper and manganese in the DTT assay. As such, the bias will be most pronounced in samples with a significant DTT contribution from copper and/or manganese, such as those used in this work. In samples such as these, which appear to be common in the U.S. based on typical particulate metal amounts (Charrier and Anastasio, 2012), a lower mass used in the DTT assay will result in higher (uncorrected) mass-normalized DTT response, even for the same sample. In general, researchers do not typically report the mass concentration of PM added to the DTT assay, or measure the concentrations of soluble $\mathrm{Cu}$ and $\mathrm{Mn}$ in their samples, so it is unclear how often this artifact affects reported DTT data in the literature. The bias will also affect a sample's air-volume-normalized DTT rate, since it is equal to the mass-normalized rate multiplied by the ambient PM mass concentration.

We also present two methods to correct mass-normalized DTT results so that they can be meaningfully compared: (1) the "interpolation" method, which uses DTT measurements at multiple PM mass concentrations for a given sample to interpolate the DTT response to an extract concentration of $10 \mu \mathrm{g} \mathrm{PM} \mathrm{mL}^{-1}$, and (2) the "calculation" method, which uses a single measured DTT response, along with the measured $\mathrm{Cu}$ and $\mathrm{Mn}$ concentrations in the sample extract, to predict the DTT response at 10 $\mu \mathrm{g} \mathrm{PM} \mathrm{mL}{ }^{-1}$. Either method can be used to correct the mass-normalized DTT response, within certain

412 over multiple PM concentrations in a relatively narrow window around $10 \mu \mathrm{g} \mathrm{PM} \mathrm{mL} L^{-1}$. In the second 413 method, "calculation", the DTT response is only measured at one PM mass concentration, but the 414 concentrations of $\mathrm{Cu}, \mathrm{Mn}$, and, preferably, other redox-active species are measured in the PM extract. 415 This method is accurate for PM concentrations greater than approximately $4 \mu \mathrm{g} \mathrm{PM} \mathrm{mL} L^{-1}$ of DTT 
solution, and can be extrapolated over a wider range of PM concentrations. It will take some work to

417 apply these corrections methods to the recently developed semi-automated and on-line DTT assays.

418 Further research into the potential effects of the mass concentration bias, and the utility of the

419 correction techniques, must be performed to ensure the integrity of this and other DTT data.

420 Additionally, the mass concentration bias observed in the DTT assay likely also occurs in any assay where

421 a major redox-active species has a non-linear concentration-response curve. This probably applies, for

422 example, to cell-free assays that measure specific reactive oxygen species, such as hydroxyl radical and

423 hydrogen peroxide, since Cu has non-linear concentration-response curves in both assays.

Finally, while mass-normalized and air-volume-normalized results from the DTT assay (and,

425 likely, other techniques) can suffer from a mass-dependence artifact, this does not impact the ability of

426 the assay to quantitatively determine which redox-active species are responsible for the measured

427 response in the mechanistic approach that has been used (e.g., Charrier and Anastasio, 2012; Charrier et

428 al., 2015). However, if non-linear species such as $\mathrm{Cu}$ and $\mathrm{Mn}$ are important in the oxidative potential

429 response, the relative importance of every redox-active species in a given PM sample will change as a

430 function of PM mass concentration used in the assay.

\section{$431 \quad 5$ Acknowledgments}

432 We thank Tobias Kraft for laboratory assistance, Joel Commisso at the UC Davis Interdisciplinary Center 433 for Plasma Mass Spectrometry for helpful discussions regarding sample preparation, and Annabelle

434 Lolinco and Kylie Markarian for assistance with the collection and preparation of $\mathrm{PM}_{2.5}$ samples.

435 Funding for this project was provided by the California Air Resources Board (agreement number 18467),

436 by the National Institute of Environmental Health Sciences (NIEHS) (grant number P42ES004699), by an

437 EPA STAR Graduate Fellowship to JC (FP-917181), by the National Science Foundation (Award number

438 1059994) and by the California Agricultural Experiment Station (Project CA-D-LAW-6403-RR). The

439 statements and conclusions in this report are those of the University and not necessarily those of the

440 California Air Resources Board or the US EPA. This publication has not been formally reviewed by ARB,

441 EPA, NIEHS, or $\mathrm{NIH}$. The mention of commercial products, their source, or their use in connection with

442 material reported herein is not to be construed as actual or implied endorsement of such products. 
Akhtar, U.S., McWhinney, R.D., Rastogi, N., Abbatt, J.P.D., Evans, G.J., Scott, J.A., 2010. Cytotoxic and proinflammatory effects of ambient and source-related particulate matter (PM) in relation to the production of reactive oxygen species (ROS) and cytokine adsorption by particles. Inhal. Tox. 22, 37-47.

Anastasio, C., Charrier, J.G., Mcfall, A.S., Vu, K.K.-T., Baroi, J., Olea, C., Paulson, S.E., Hasson, A.S., In Preparation. Dithiothreitol (DTT) Redox-Activity of Particulate Matter from Two Sites in California. Chemosphere.

Biswas, S., Verma, V., Schauer, J.J., Cassee, F.R., Cho, A.K., Sioutas, C., 2009. Oxidative Potential of SemiVolatile and Non Volatile Particulate Matter (PM) from Heavy-Duty Vehicles Retrofitted with Emission Control Technologies. Env. Sci. Technol. 43, 3905-3912.

Charrier, J.G., Anastasio, C., 2011. Impacts of antioxidants on hydroxyl radical production from individual and mixed transition metals in a surrogate lung fluid. Atmos. Environ. 45, 7555-7562.

Charrier, J.G., Anastasio, C., 2012. On dithiothreitol (DTT) as a measure of oxidative potential for ambient particles: evidence for the importance of soluble transition metals. Atmos. Chem. Phys. 12, 9321-9333.

Charrier, J.G., Mcfall, A.S., Richards-Henderson, N.K., Anastasio, C., 2014. Hydrogen peroxide formation in a surrogate lung fluid by transition metals and quinones present in particulate matter Env. Sci. Technol. 48, 7010-7017.

Charrier, J.G., Anastasio, C., 2015. Rates of hydroxyl radical production from transition netals and quinones in a surrogate lung fluid. Env. Sci. Technol. 4, 9317-9325.

Charrier, J.G., Richards-Henderson, N.K., Bein, K.J., Mcfall, A.S., Wexler, A.S., Anastasio, C., 2015. Oxidant production from source-oriented particulate matter - Part 1: Oxidative potential using the dithiothreitol (DTT) assay. Atmos. Chem. Phys. Accepted.

Cho, A.K., Di Stefano, E., You, Y., Rodriguez, C.E., Schmitz, D.A., Kumagai, Y., Miguel, A.H., EigurenFernandez, A., Kobayashi, T., Avol, E., Froines, J.R., 2004. Determination of four quinones in diesel exhaust particles, SRM 1649a, an atmospheric PM2.5. Aerosol Sci. Technol. 38, 68-81.

Cho, A.K., Sioutas, C., Miguel, A.H., Kumagai, Y., Schmitz, D.A., Singh, M., Eiguren-Fernandez, A., Froines, J.R., 2005. Redox activity of airborne particulate matter at different sites in the Los Angeles Basin.

Environ. Res. 99, 40-47.

Chung, M.Y., Lazaro, R.A., Lim, D., Jackson, J., Lyon, J., Rendulic, D., Hasson, A.S., 2006. Aerosol-borne quinones and reactive oxygen species generation by particulate matter extracts. Env. Sci. Technol. 40, 4880-4886.

Delfino, R.J., Staimer, N., Tjoa, T., Gillen, D.L., Schauer, J.J., Shafer, M.M., 2013. Airway inflammation and oxidative potential of air pollutant particles in a pediatric asthma panel. J. Expo. Sci. Environ. Epidemiol. 23, 466-473.

DiStefano, E., Eiguren-Fernandez, A., Delfino, R.J., Sioutas, C., Froines, J.R., Cho, A.K., 2009. Determination of metal-based hydroxyl radical generating capacity of ambient and diesel exhaust particles. Inhal. Tox. 21, 731-738. 
Fang, T., Verma, V., Guo, H., King, L.E., Edgerton, E.S., Weber, R.J., 2015. A semi-automated system for quantifying the oxidative potential of ambient particles in aqueous extracts using the dithiothreitol (DTT) assay: results from the Southeastern Center for Air Pollution and Epidemiology (SCAPE). Atmos. Meas. Tech. 8, 471-482.

Geller, M.D., Ntziachristos, L., Mamakos, A., Samaras, Z., Schmitz, D.A., Froines, J.R., Sioutas, C., 2006. Physicochemical and redox characteristics of particulate matter (PM) emitted from gasoline and diesel passenger cars. Atmos. Environ. 40, 6988-7004.

Hu, S., Polidori, A., Arhami, M., Shafer, M.M., Schauer, J.J., Cho, A., Sioutas, C., 2008. Redox activity and chemical speciation of size fractioned PM in the communities of the Los Angeles-Long Beach harbor. Atmos. Chem. Phys. 8, 6439-6451.

Koehler, K., Shapiro, J., Sameenoi, Y., Henry, C.S., Volckens, J., 2014. Laboratory evaluation of a microfluidic electrochemical sensor for aerosol oxidative load. Aerosol Sci. Technol. 48, 489-497.

Kramer, A.J., Rattanavaraha, W., Zhang, Z., Gold, A., Surratt, J.D., Lin, Y.H., 2016. Assessing the oxidative potential of isoprene-derived epoxides and secondary organic aerosol. Atmos. Environ. 130, 211-218.

Li, Q.F., Wyatt, A., Kamens, R.M., 2009. Oxidant generation and toxicity enhancement of aged-diesel exhaust. Atmos. Environ. 43, 1037-1042.

Lin, P., Yu, J.Z., 2011. Generation of reactive oxygen species mediated by humic-like substances in atmospheric aerosols. Env. Sci. Technol. 45, 10362-10368.

McWhinney, R.D., Badali, K., Liggio, J., Li, S.M., Abbatt, J.P.D., 2013a. Filterable Redox Cycling Activity: A Comparison between Diesel Exhaust Particles and Secondary Organic Aerosol Constituents. Env. Sci. Technol. 47, 3362-3369.

McWhinney, R.D., Zhou, S., Abbatt, J.P.D., 2013b. Naphthalene SOA: redox activity and naphthoquinone gas-particle partitioning. Atmos. Chem. Phys. 13, 9731-9744.

Rattanavaraha, W., Rosen, E., Zhang, H.F., Li, Q.F., Pantong, K., Kamens, R.M., 2011. The reactive oxidant potential of different types of aged atmospheric particles: An outdoor chamber study. Atmos. Environ. 45, 3848-3855.

Richards-Henderson, N.K., Charrier, J.G., Bein, K.J., Bau, D., Wexler, A.S., Anastasio, C., 2015. Oxidant production from source-oriented particulate matter - Part 2: Hydrogen peroxide and hydroxyl radical. Atmos. Chem. Phys. In Preparation.

Saffari, A., Daher, N., Shafer, M.M., Schauer, J.J., Sioutas, C., 2014. Seasonal and spatial variation in dithiothreitol (DTT) activity of quasi-ultrafine particles in the Los Angeles Basin and its association with chemical species. J. Environ. Sci. Health Part A-Toxic/Hazard. Subst. Environ. Eng. 49, 441-451.

Sameenoi, Y., Koehler, K., Shapiro, J., Boonsong, K., Sun, Y., Collett, J., Volckens, J., Henry, C.S., 2012. Microfluidic electrochemical sensor for on-line monitoring of aerosol oxidative activity. Journal of American Chemical Society 134, 10562-10568.

Sameenoi, Y., Panymeesamer, P., Supalakorn, N., Koehler, K., Chailapakul, O., Henry, C.S., Volckens, J., 2013. Microfluidic paper-based analytical device for aerosol oxidative activity. Env. Sci. Technol. 47, 932940. 
Sauvain, J.J., Deslarzes, S., Riediker, M., 2008. Nanoparticle reactivity toward dithiothreitol.

521 Nanotoxicology 2, 121-129.

522 Shen, H., Anastasio, C., 2011. Formation of hydroxyl radical from San Joaquin Valley particles extracted 523 in a cell-free surrogate lung fluid. Atmos. Chem. Phys. 11, 9671-9682.

524 Shen, H., Barakat, A.I., Anastasio, C., 2011. Generation of hydrogen peroxide from San Joaquin Valley

525 particles in a cell-free solution. Atmos. Chem. Phys. 11, 753-765.

526 Shen, H., Anastasio, C., 2012. A comparison of hydroxyl radical and hydrogen peroxide generation in 527 ambient particle extracts and laboratory metal solutions. Atmos. Environ. 46, 665-668.

528

529

530

531

532

533

534

535

536

537

538

539

540

541

542

543

544

545

546

547

548

549

550

551

552

553

554

555

556
Steenhof, M., Gosens, I., Strak, M., Godri, K.J., Hoek, G., Cassee, F.R., Mudway, I.S., Kelly, F.J., Harrison, R.M., Lebret, E., Brunekreef, B., Janssen, N.A.H., Pieters, R.H.H., 2011. In vitro toxicity of particulate matter (PM) collected at different sites in the Netherlands is associated with PM composition, size fraction and oxidative potential - the RAPTES project. Part. Fibre Toxicol. 8.

Verma, V., Ning, Z., Cho, A.K., Schauer, J.J., Shafer, M.M., Sioutas, C., 2009a. Redox activity of urban quasi-ultrafine particles from primary and secondary sources. Atmos. Environ. 43, 6360-6368.

Verma, V., Polidori, A., Schauer, J.J., Shafer, M.M., Cassee, F.R., Sioutas, C., 2009b. Physicochemical and toxicological profiles of particulate matter in Los Angeles during the October 2007 Southern California wildfires. Env. Sci. Technol. 43, 954-960.

Verma, V., Pakbin, P., Cheung, K.L., Cho, A.K., Schauer, J.J., Shafer, M.M., Kleinman, M.T., Sioutas, C., 2011. Physicochemical and oxidative characteristics of semi-volatile components of quasi-ultrafine particles in an urban atmosphere. Atmos. Environ. 45, 1025-1033.

Verma, V., Rico-Martinez, R., Kotra, N., King, L., Liu, J.M., Snell, T.W., Weber, R.J., 2012. Contribution of Water-Soluble and Insoluble Components and Their Hydrophobic/Hydrophilic Subfractions to the Reactive Oxygen Species-Generating Potential of Fine Ambient Aerosols. Env. Sci. Technol. 46, 1138411392.

Verma, V., Fang, T., Guo, H., King, L., Bates, J.T., Peltier, R.E., Edgerton, E., Russell, A.G., Weber, R.J., 2014. Reactive oxygen species associated with water-soluble PM2.5 in the southeastern United States: spatiotemporal trends and source apportionment. Atmos. Chem. Phys. 14, 12915-12930.

Verma, V., Fang, T., Xu, L., Peltier, R.E., Russell, A.G., Ng, N.L., Weber, R.J., 2015a. Organic aerosols associated with the generation of reactive oxygen species (ROS) by water-soluble PM2.5. Env. Sci. Technol. 49, 4646-4656.

Verma, V., Wang, Y., El-Afifi, R., Fang, T., Rowland, J., Russell, A.G., Weber, R.J., 2015b. Fractionating ambient humic-like substances (HULIS) for their reactive oxygen species activity - Assessing the importance of quinones and atmospheric aging. Atmos. Environ. 120, 351-359.

Vidrio, E., Jung, H., Anastasio, C., 2008. Generation of hydroxyl radicals from dissolved transition metals in surrogate lung fluid solutions. Atmos. Environ. 42 4369-4379.

Vidrio, E., Phuah, C.H., Dillner, A.M., Anastasio, C., 2009. Generation of hydroxyl radicals from ambient fine particles in a surrogate lung fluid solution. Env. Sci. Technol. 43, 922-927. 
557 Yang, A., Wang, M., Eeftens, M., Beelen, R., Dons, E., Leseman, D.L., Brunekreef, B., Dons, E., Leseman, 558 D.L.A.C., Cassee, F.R., Janssen, A.H., Hoek, G., 2015. Spatial variation and land use regression modeling 559 of the oxidative potential of fine particles. Environ. Health Perspect. Advanced Publication.

560 Yang, H., Liu, C., Yang, D.F., Zhang, H.S., Xi, Z.G., 2009. Comparative study of cytotoxicity, oxidative stress 561 and genotoxicity induced by four typical nanomaterials: the role of particle size, shape and composition. 562 J. Appl. Toxicol. 29, 69-78.

563

564 
Figure 1. DTT Response from a theoretical particle sample in units of (a) $\mu \mathrm{M}$ DTT $\mathrm{min}^{-1}$ (linear scale) and (b) pmols DTT $\mathrm{min}^{-1} \mathrm{\mu g}^{-1}$-PM (log scale). The theoretical PM sample would produce soluble concentrations of $100 \mathrm{nM} \mathrm{Cu}, 150 \mathrm{nM} \mathrm{Mn}, 150 \mathrm{nM} \mathrm{Co}$, and $5 \mathrm{nM}$ PQN at a mass concentration of $10 \mu \mathrm{g}$ $\mathrm{PM} \mathrm{mL} \mathrm{L}^{-1}$ of DTT solution.

Figure 2. Calculated contributions of soluble metals and quinones to the measured DTT response for eight ambient $\mathrm{PM}_{2.5}$ samples. The PM mass concentration added to the DTT assay for each sample is given below the $x$-axis label. For each sample the total bar height represents the measured DTT response, and the colored components of the bar are the calculated contributions from individual chemical components, using measured component concentrations and the concentration-response curves from Charrier and Anastasio (2012). The grey portion of the bar represents the DTT response 576 from unknown species.

577 Figure 3. Measured DTT response as a function of PM concentration added to the assay for the eight ambient $\mathrm{PM}_{2.5}$ samples. Data are displayed in two units (a) $\mu \mathrm{M}$ DTT $\mathrm{min}^{-1}$, and (b) pmols DTT $\mathrm{min}^{-1} \mu \mathrm{g}^{-1}$ PM. Each color represents an individual sample (Table 1).

Figure 4. Summary of results from sample C12, including the measured soluble Cu concentration (right Y-axis), and measured DTT rate and calculated DTT rate from $\mathrm{Cu}$ (left Y-axis) for (a) the raw measurement, and (b) the mass-normalized measurement.

Figure 5. Measured rate of DTT response (blue circles) and the corrected rate determined at $10 \mu \mathrm{g}$ PM $\mathrm{mL}^{-1}$ using the "interpolation" method (black $\mathrm{x}$ ) for each PM sample. The black line represents the linear regression fit to the measured DTT response, which was used to interpolate (or extrapolate) the DTT response to a PM concentration of $10 \mu \mathrm{g} \mathrm{m}^{-1}$. The orange line in panel $(\mathrm{g})$ represents the calculated DTT response based on the chemical composition of the sample measured at $65.9 \mu \mathrm{g} \mathrm{PM} \mathrm{mL}^{-1} \mathrm{DTT}$ 588 solution.

589 Figure 6. Corrected mass-normalized DTT response using the "calculated" method as a function of 590 starting PM mass concentration.

591 Figure 7. Corrected mass-normalized DTT rate for each sample determined using two methods, 592 compared to the measured DTT rate.

Table 1. Summary of Samples used for Variable Mass Analyses

\begin{tabular}{|c|l|r|r|r|r|r|}
\hline Sample ID & \multicolumn{1}{|c|}{ Location } & Date & Period & Time & $\begin{array}{c}\text { Number of PM } \\
\text { Concentrations }\end{array}$ & $\begin{array}{c}\text { Range of PM } \\
\text { Concentrations } \\
\text { Used in DTT Assay } \\
\text { Used in DTT assay }\end{array}$ \\
\hline C12 & Claremont, CA & $7 / 29-7 / 30 / 2012$ & Overnight & $18: 30-7: 12$ & 9 & $1.6-34.2$ \\
\hline C19 & Claremont, CA & $8 / 1 / 2012$ & Morning & $7: 23-13: 12$ & 5 & $2.2-7.5$ \\
\hline C28 & Claremont, CA & $8 / 4 / 2012$ & Morning & $7: 27-13: 15$ & 5 & $2.1-10.7$ \\
\hline C49 & Claremont, CA & $8 / 11 / 2012$ & Morning & $7: 22-13: 05$ & 3 & $2.7-10.7$ \\
\hline C54 & Claremont, CA & $8 / 12-8 / 13 / 2012$ & Overnight & $18: 17-7: 13$ & 4 & $4.0-24.5$ \\
\hline F17 & Fresno, CA & $1 / 20 / 2013$ & Afternoon & $13: 10-18: 00$ & 2 & $15.4-27$ \\
\hline F28 & Fresno, CA & $1 / 24-1 / 25 / 2013$ & Overnight & $18: 13-8: 26$ & 2 & $37.6-65.9$ \\
\hline F42 & Fresno, CA & $1 / 30 / 2013$ & Afternoon & $13: 12-17: 58$ & 2 & $5.6-9.9$ \\
\hline
\end{tabular}


Figure 1.

(a)
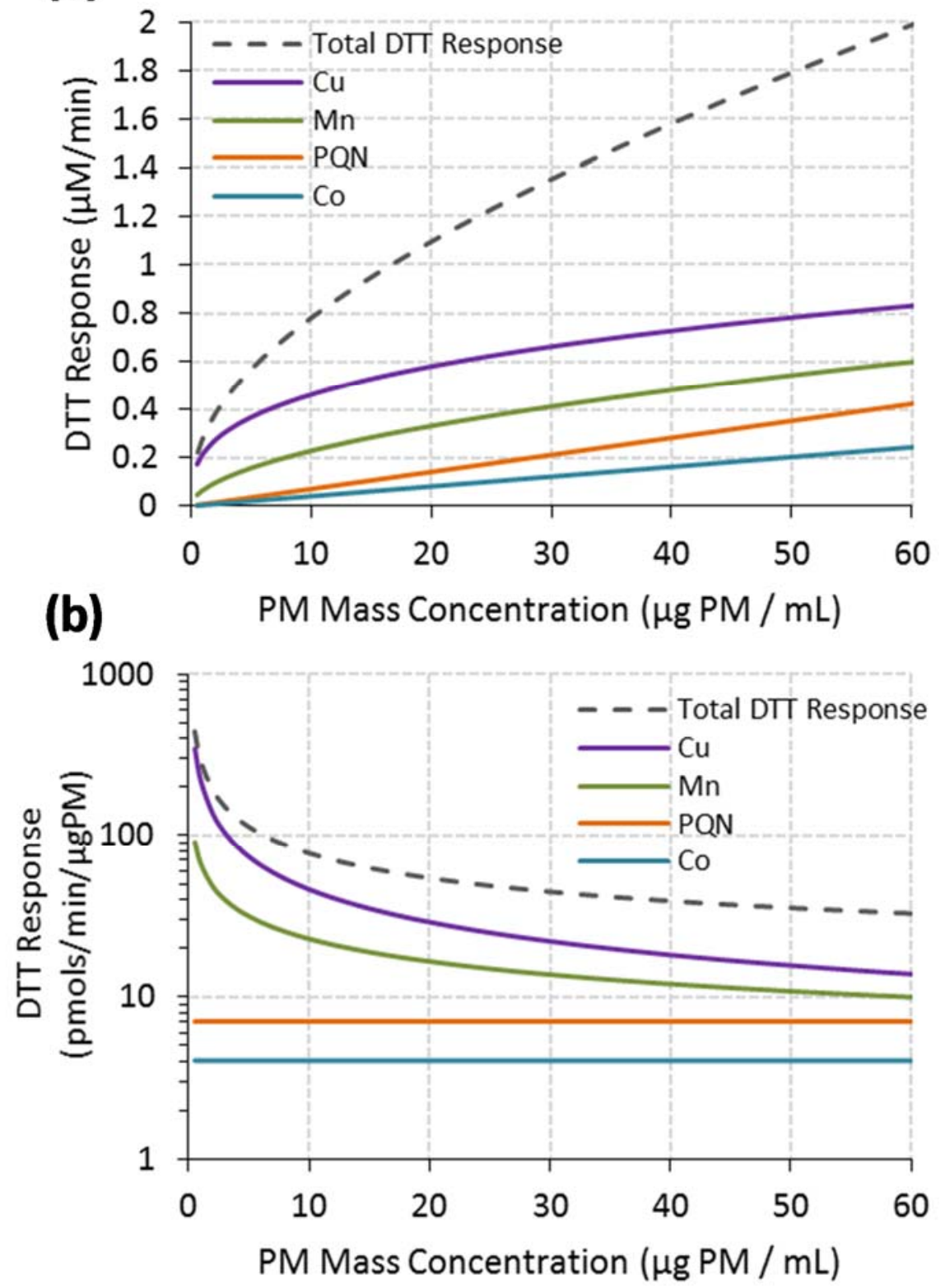
Figure 2.

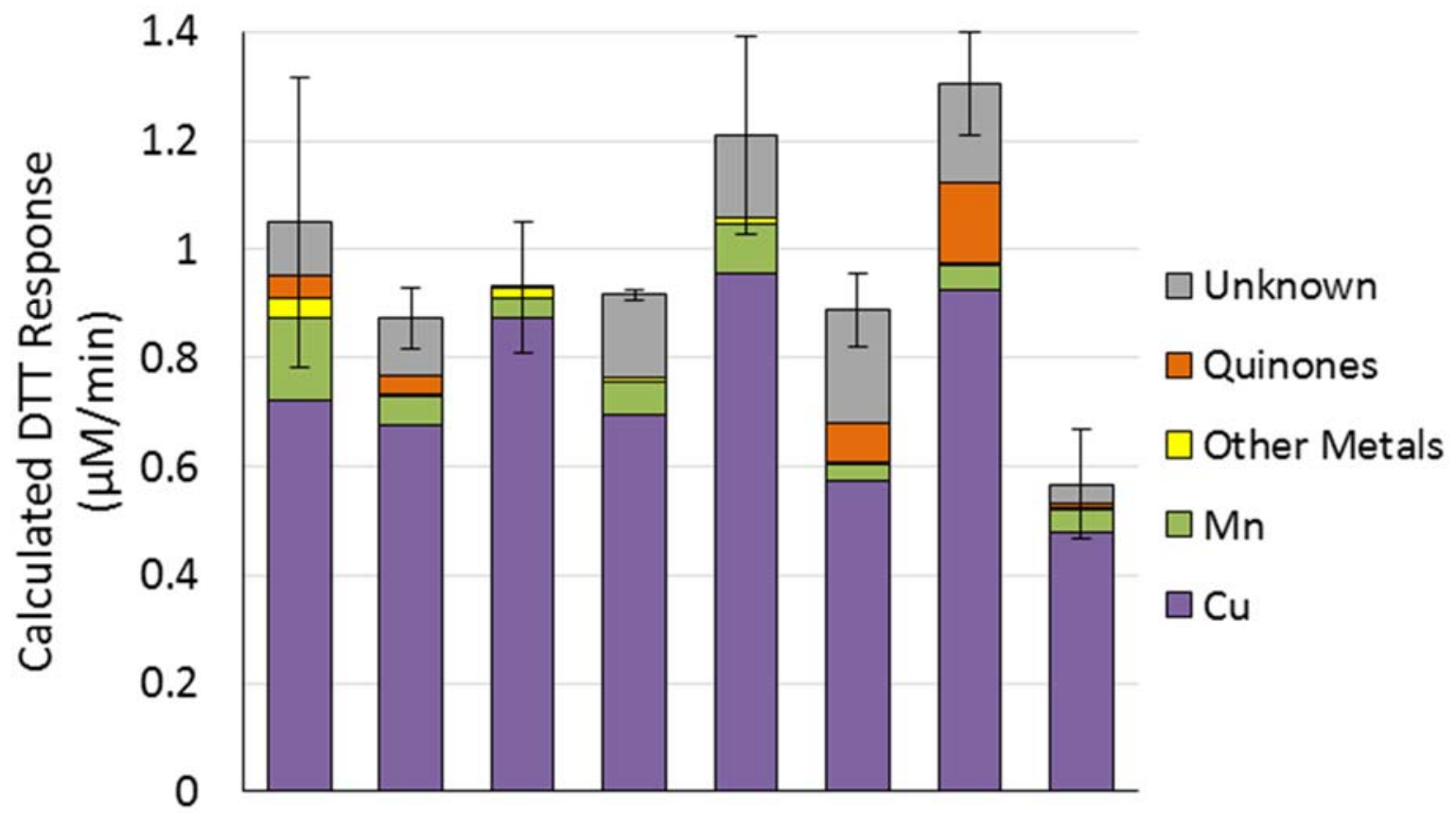

Sample ID: $\begin{array}{llllllll}\text { C12 } & \text { C19 } & \text { C28 } & \text { C49 } & \text { C54 } & \text { F17 } & \text { F28 } & \text { F42 }\end{array}$

610

$\begin{array}{lllllllll}\text { PM Mass }(\mu \mathrm{g} / \mathrm{mL}): & 19.5 & 7.5 & 10.7 & 10.7 & 13.9 & 15.4 & 37.6 & 5.6\end{array}$

611

612

613

614

615

616

617

618

619

620

621

622

623

624

625

626

627

628

629

630

631

632

633

634 
Figure 3.
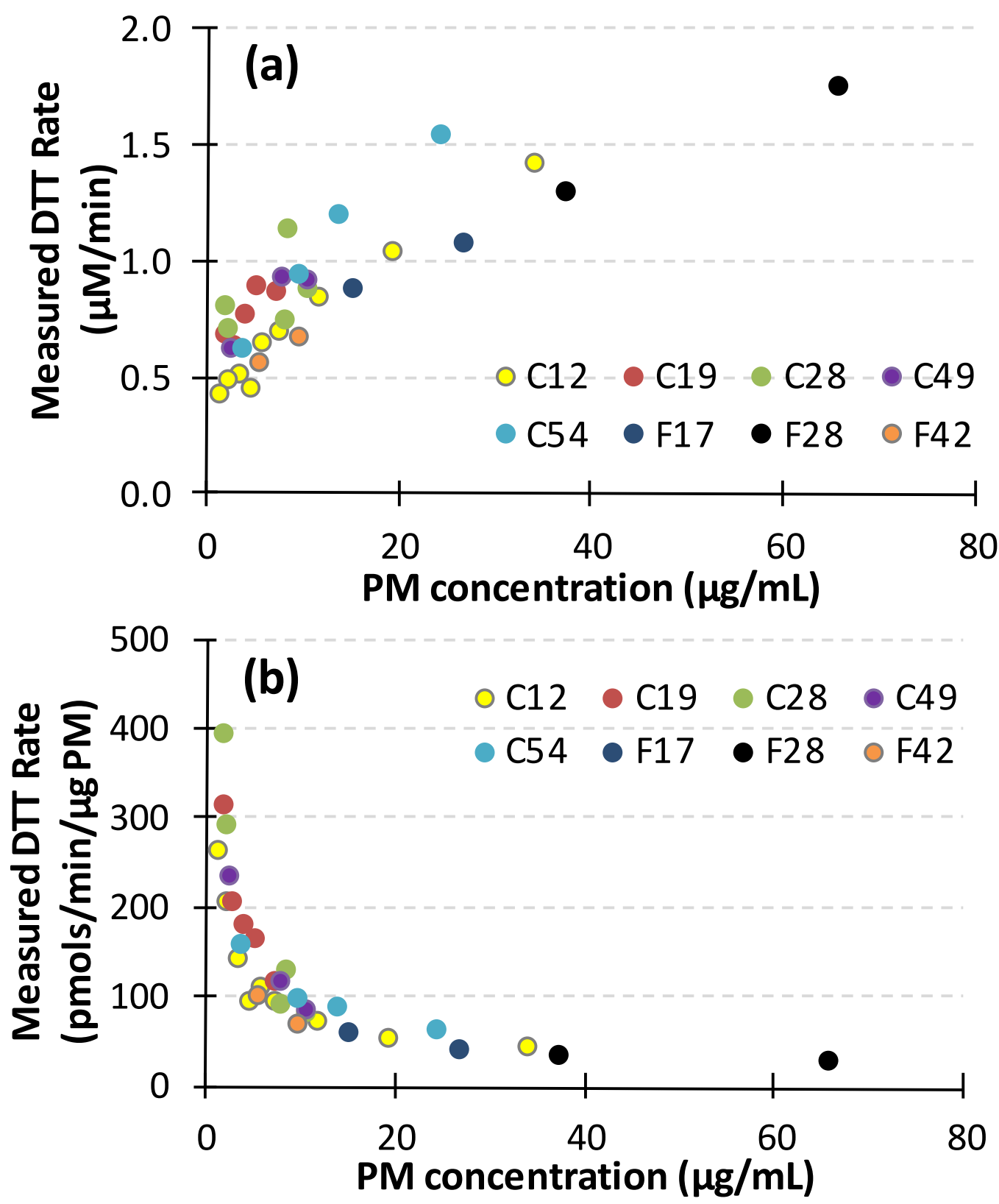
Figure 4.

(a)

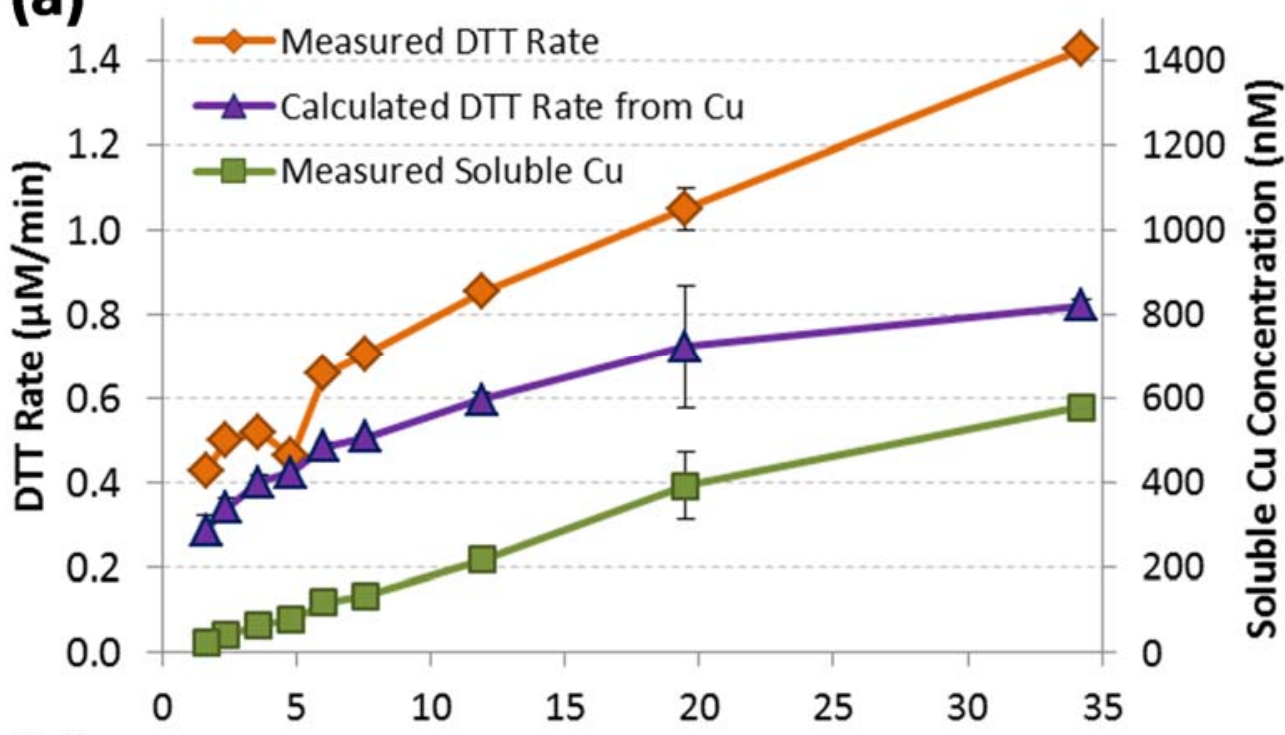

(b) PM Mass Concentration $(\mu \mathrm{g} / \mathrm{mL})$

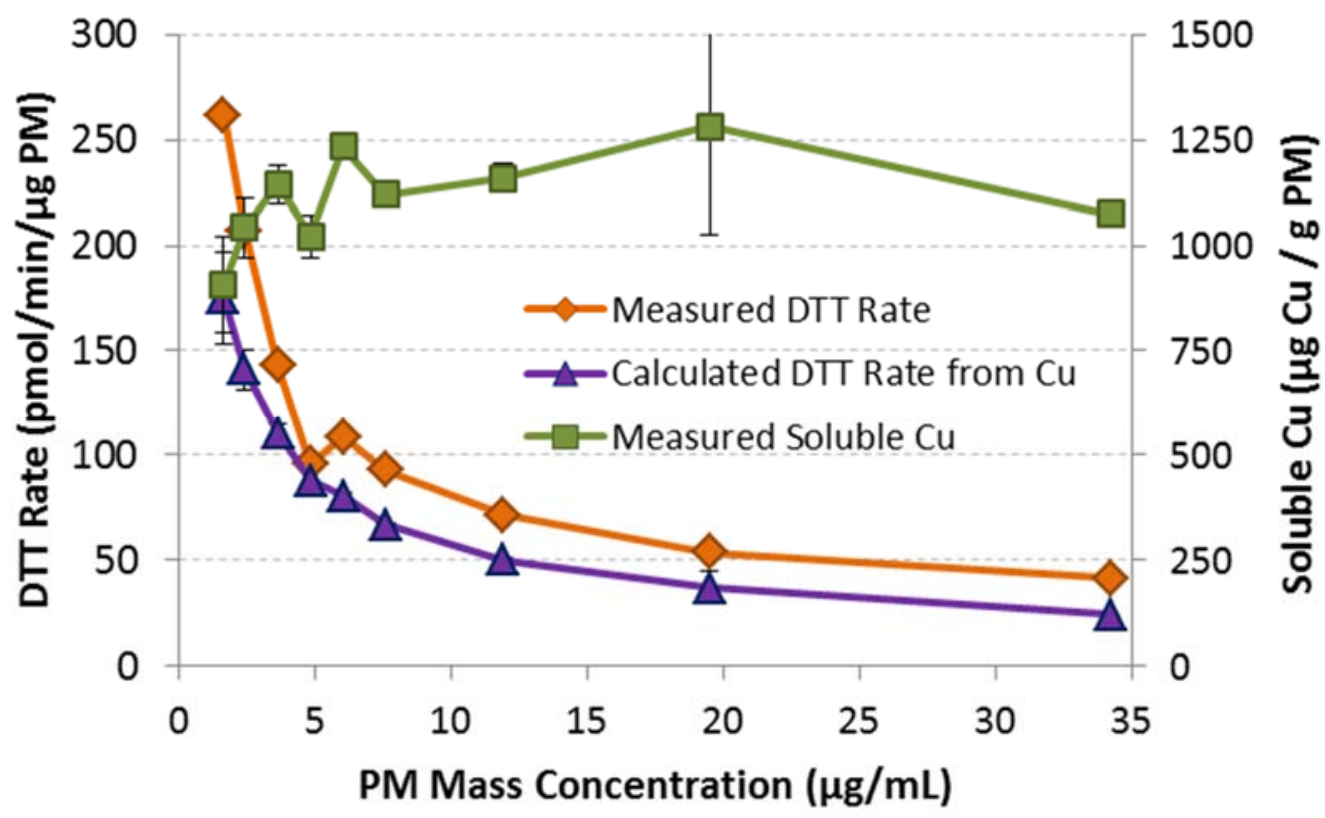

649

650

651

652

653

654

655

656

657

658

659 


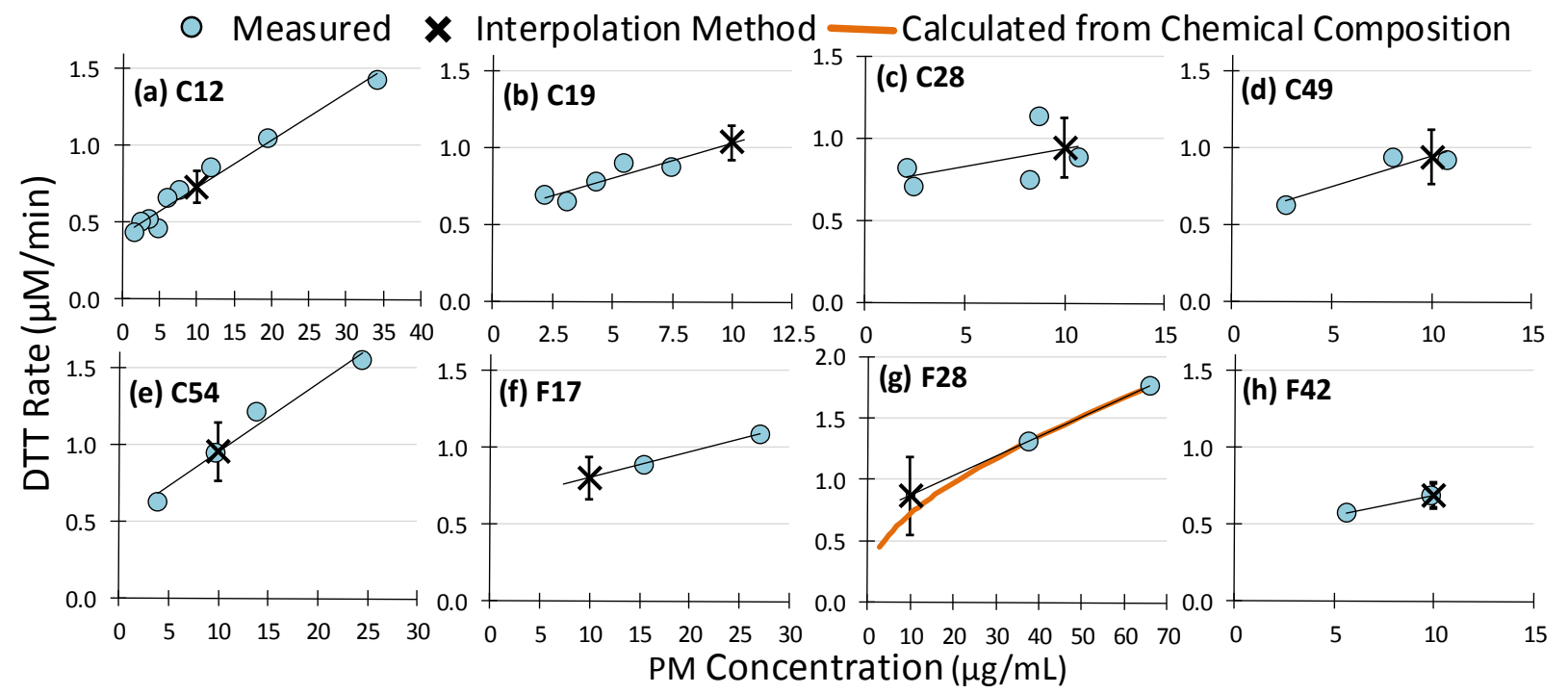

661

662

663

664

665

666

667

668

669

670

671

672

673

674

675

676

677

678

679

680

681

682

683

684

685

686

687

688

689

690 
691 Figure 6.
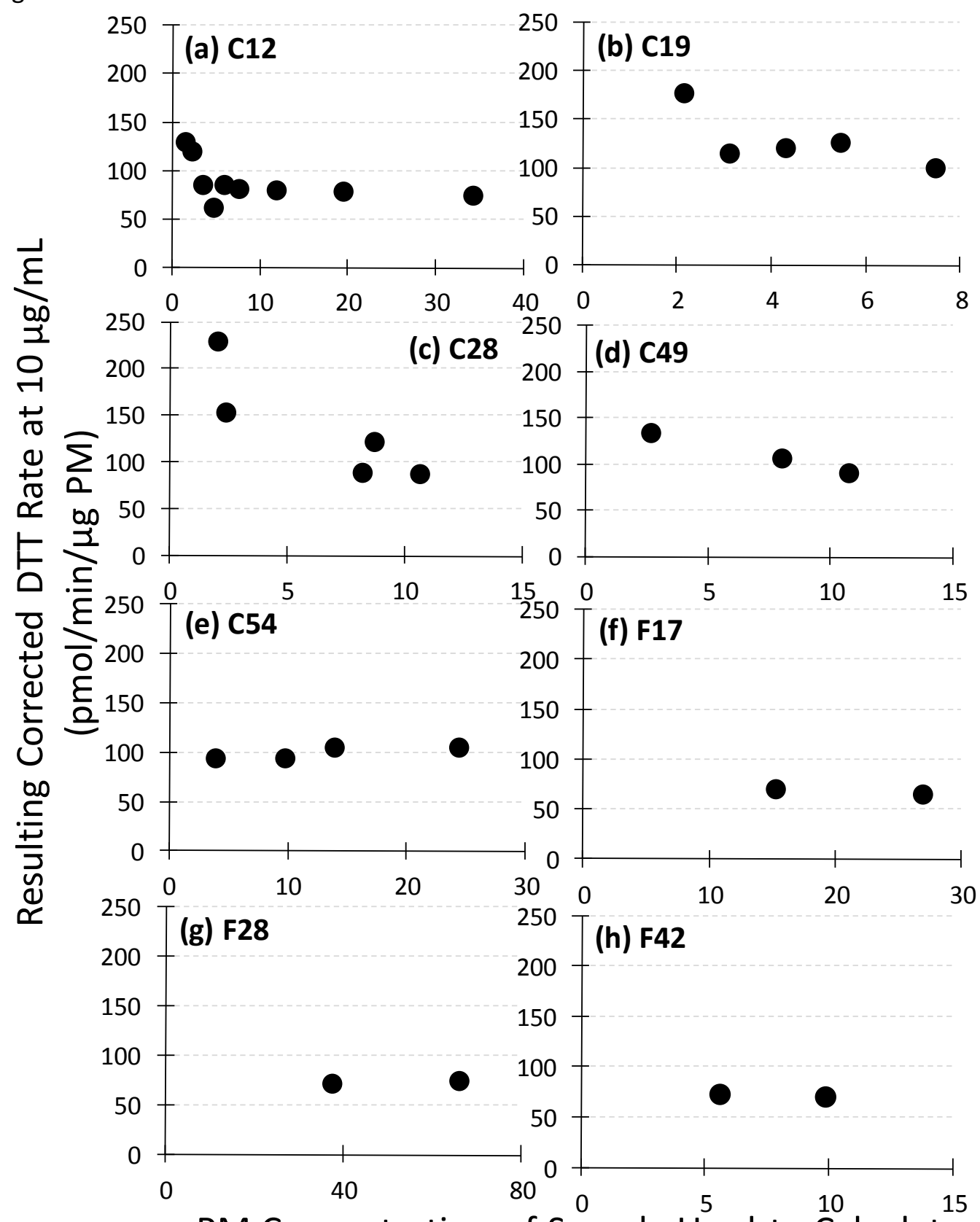

PM Concentration of Sample Used to Calculate Corrected DTT Response at $10 \mu \mathrm{g} / \mathrm{mL}$

692

693

694

695

696

697

698

699

700 
Figure 7.

- Measured $\Delta$ Calculated Method $\times$ Interpolation Method
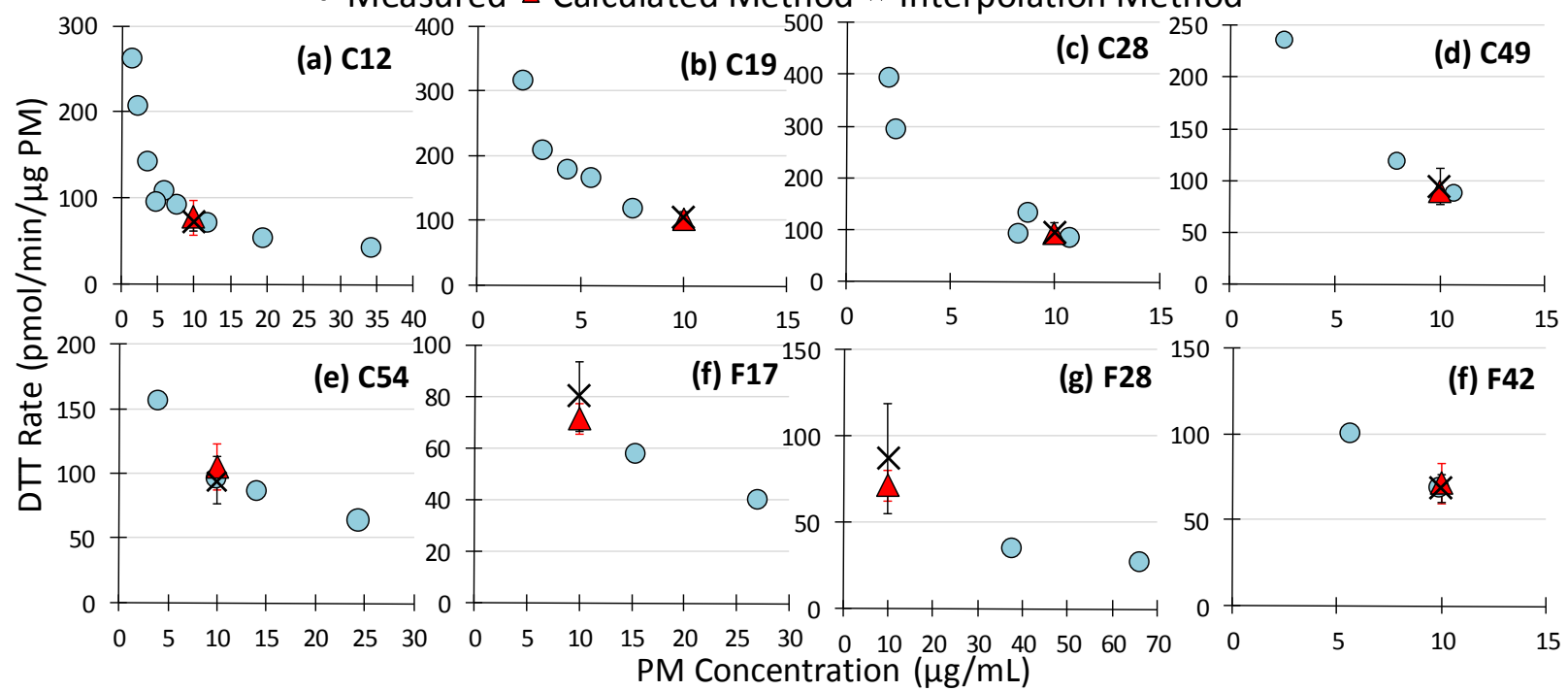

702

703

704 